\title{
RESEÑA
}

\section{GIORGIO AGAMBEN, ESTADO DE EXCEPCIÓN. BUENOS AIRES: ADRIANA HIDALGO EDITORA, 2005, 172 PÁGS.}

\author{
José Luis Aguilar \\ Universidad \\ Tecmilenio \\ jfydn@hotmail.com
}

\section{DOI: https://doi.org/10.38128/cienciayfilosofa.v1i01.7}

El título de la obra es ya un ejemplo de la noción de límite al que llegan las democracias representativas que parecían haber erradicado el concepto jurídico-político de dictadura. El último tercio del siglo XX estuvo invadido por todo un arsenal literario jurídico-filosófico para desterrar definitivamente las nociones de totalitarismo y las variantes de dictadura que mantenían los estados nacionales fuertemente centralizados en los poderes ejecutivos. Sin embargo, el libro de Agamben muestra la ironía a la que llegaron estos razonamientos que defienden a las democracias representativas que, según ellos, habían excluido de su interior las técnicas de concentración de poder por parte de los ejecutivos y jueces en las democracias constitucionales (verbigracia Bobbio, Sartori entre otros).

Con la introducción del concepto de democracia gubernamental, se ciñe una noción de límite en los procedimientos de legitimación de un gobierno democrático respecto al ejercicio de poder concentrado en un ejecutivo que define su práctica política superando a la norma constitucional vigente, de este modo surge la paradoja entre orden constitucional y poder ejecutivo ejercido por encima de la norma constitucional. 
En otros términos, se trata de la oposición que hay entre nomos y anomía, que supuestamente había sido erradicado del discurso político en el último tercio del siglo XX, es ahora puesta en cuestión en el concepto de democracia gubernamental que desarrolla Agamben.

Aunque también hay que señalar que Estado de excepción constituye una continuidad de la metodología arqueológica para despolarizar las categorías jurídicopolíticas que definen la tradición del ejercicio del poder en las democracias occidentales. En este sentido, no se trata de un nuevo giro sintáctico para priorizar el concepto de democracia representativa, sino de la eliminación de las paradojas polarizantes (democracia versus totalitarismo) fundamentando una nueva semántica del poder surgida en el juego de categorías sobre la violencia mítica y la violencia pura.

Agamben no solo es heredero de la tradición crítica de Benjamin pasando por Foucault y Derrida sino que vuelve al estudio filológico del derecho romano para resemantizar la oposición de dictadura que sostiene Carl Schmitt en la década de los 20’s del siglo pasado. Centremos el análisis en este último punto.

Con Schmitt la evolución del concepto romano de dictadura sufre una nueva transformación a partir de la Revolución Francesa, al oponer la práctica política del concepto moderno de soberanía: la dictadura comisarial y la dictadura soberana, marcan los dos momentos fundacionales de un Estado incluido en la noción de poder constituyente y poder constituido. En cambio para Agamben, los conceptos de dictadura comisarial (constituida) y soberana (constituyente) obedecen a un paradigma por demás cuestionado por Benjamin: la violencia en cuento poder fundante se encamina en un solo sentido, la juridización del poder.

Retomando la idea benjaminiana de violencia pura, el análisis a la crítica de la oposición schmittiana de dictadura comisarial y dictadura soberana no encuentra salida a esta antítesis: puesto que para Schmitt las categorías de necesidad y decisión política en un momento preconstituyente, constituyente y posconstituyente no tienen otra salida más que la de la violencia mítica, es decir, la lógica de la violencia en Schmitt no es más que la 
violencia jurídica o si se prefiere, la juridización de la violencia. Lo jurídico sin violencia es impensable para la fundación estatal.

Hasta aquí, Agamben sigue a Benjamín, sin embargo, continua indagando la sospecha de Derrida, según la cual, habiendo normas supremas y normas menores, el poder ejercido por los hombres (como son los ejecutivos y jueces) crean un lugar de anomia que determina la fisionomía del poder en términos de ejercicio de la voluntad política de un gobernante, es decir, crear y mantener un poder que tiene fuerza de ley sin emanar de la ley misma.

Colateralmente, el análisis sugiere que la vieja teoría de la emanación del poder a partir de la ley es superada en las democracias gumernamentales, lo mismo sucede con la teoría de la balanza de poderes ya que es cuestionado su mecanismo en las constituciones republicanas modernas en donde se apertura un espacio en el ejercicio del poder que tiene fuerza de ley pero que no está previsto constitucionalmente, sobre todo en aquellas constituciones garantistas por o posición a las modernas constituciones de derecho, vinculadas al derecho convencional internacional.

Volviendo a la obra en cuestión, Agamben recursa investigar el derecho romano, que es donde se origina la resemantización de la que hemos hablado. Analizando el concepto de pater legibus, Agamben describir las antiguas instituciones romanas en donde las leyes acallaban no necesariamente para nombrar un momento de necesidad estatal frente a la crisis de Estado, sea por sedición o por invasión, es decir, lo que intenta dejar claro el autor en cuestión es que la oposición entre nomos y anomía; fiesta, luto y anomía y por supuesto, autoritas y potestas se comprende ante un vacío de violencia juridizada, es decir, antiguamente existió un espacio de libertad en donde los hombres convivía conforme a sus tradición religiosa cuando las leyes callaban.

Por tanto, el conocimiento de la práctica de conformación de espacio vacío, anómico, es lo que caracteriza la obra que estamos reseñando, sin embargo, nos gustaría agregar lo siguiente. 
Si bien Agamben llega a desarticular la concepción de dictadura schmittiana a partir de la violencia pura de Benjamin hasta encontrar el espacio vacío anómico desarticulado de la violencia jurídica (constituyente fundamentalmente) no obstante en cuanto al concepto de pater legibus ha queda intacto.

Esto es, el análisis que hace Agamben desarticula al estado padre, consecuente con la simbólica de la mismidad de Dios padre, pero en cuanto a las relaciones no estatales, es decir económicas, el espacio vacío anómico no alcanza a desarticular la misma lógica paternal de la economía política burguesa. Simplemente el patrón burgués que reparte salarios, vivienda y seguridad social consecuente son la simbólica del pater legibus ha quedado intacto, y es más, la categoría de dictadura proletaria que se presentaba como un momento fundacional a partir de una destrucción estatal se encuentra arqueológicamente descuidado del análisis del estado de sitio como síntoma manifiesto de las crisis económico-políticos que se producen en los estado nacionales modernos.

Reconstruyamos este último punto a partir de un supuesto de la tradición crítica que es precisamente el supuesto sobre el proceso en la historia.

En el proceso histórico capitalista hay un momento de indefinición conceptual que requiere ser fundado y por tanto fundamentado con una lógica diferente a la violencia mítica (que es el eje de ataque de Benjamin y por su puesto de Agamben).

Al respecto, Marx propuso el concepto de dictadura proletaria para definir un momento de "intervención severa" (Aguilar, 2016a: 166-186) en la constitución de los estados. Por su parte, la tradición marxista había entendido por dictadura una continuidad de la concepción jacobina del pueblo como educador de la nueva conciencia social (Draper, 1987: 30 ss), no obstante, los estudios que hemos realizado (Aguilar, $2016 \mathrm{~b}: 171 \mathrm{ss)}$ ) sobre la dictadura en Schmitt, señalan que la dictadura proletaria no se implicaba a partir de una concepción del derecho romano, en este caso pater populus, sino que en el supuesto de la dictadura soberana se hace referencia a una transición de un Estado de Derecho hacia un Estado Económico o situación económica que motiva un orden de naturaleza diferente a los ordenes jurídicos como los conocemos hasta ahora, es decir, que la transición o transformación de naturaleza de un orden jurídico hacia otro distinto, no se explica a partir 
del concepto de dictadura. Podemos, que en este punto existe hasta ahora, en la tradición crítica, un ciento acuerdo al respecto.

Por su parte, Agamben sugiere, a partir del texto en cuestión, descartar la orientación fundacionista de orden jurídico que sigue la constitución del Estado moderno, pero no indica la naturaleza de transformación, no al menos como lo sugiere White y recientemente Karatani.

Para el análisis marxiano que hace White sobre la naturaleza de la transformación, es decir, transitar de un orden jurídico o de derecho, hacia una nueva situación económica, significa transitar de una forma de conciencia públicamente sancionada a otra, en donde la conciencia de transformación no atraviese por procedimientos metafóricos, de sinécdoque o metonimia (White, 1992: 292) sino por otros medios de naturaleza equivalencial.

Esto sugiere que la juridización de la violencia atraviesa por el recorrido de la conciencia de transformación que expone White en los procesos de transformación histórica implicados por Marx, es decir, en el proceso histórico capitalista no es suficiente con destruir al Estado, tampoco fundamentar una transición de Estado con orientación jurídica violenta como supone la lectura marxista sobre el concepto de dictadura proletaria (de carácter leninista), sino que la resemantización acerca del estado de excepción implica nuevas formas equivalenciales más allá de la lógica simbólica del pater legibus que distribuye salarios, vivienda y seguridad social.

Por su parte, Karatani (2003: 182 ss) rescata la descripción que hace Marx sobre el parricidio que acomete la Comuna de 1792 ante la figura del padre ejecutor de leyes y mandatos, es decir, la destrucción de la figura vertizalizante del ejecutivo, sobre todo del juez. La muerte simbólica de las figuras ejecutivas que es narrada por Marx, se orientan, según Karatani, hacia la conformación de una teoría de la asociación que no parte del logos separatista de tres poderes en donde el ejecutivo y el juez son reflejos del pater legibus y por tanto se identifican con la violencia mítica, y con la concepción de fuerza de orientación jurídica en la tradición contractualista y convencional de los siglos XVII y XVIII. 
Según este último punto, una teoría de la asociación marxiana definiría no solamente un espacio de violencia pura sin medios ni finalidades, sino un momento de acracia consecuente con la teoría anarquista. Tal vez este sea el horror que provoca una simbólica de la violencia sin dioses, ni héroes puesto que en la acracia solo caben las virtudes humanas.

En consecuencia, tratar con la noción de límite $\pi \dot{\varepsilon} \rho \alpha \varsigma$ significa nombrar un nuevo procedimiento cuando una lógica ya no funciona, sea racional (deductiva-inferencial) o simbólica (imaginaria). En el texto en cuestión son ambas lógicas las que han agotado el ejercicio del poder como lo conocemos en las democracias occidentales, razón por la cual este texto es recomendado para tratar la noción de límite aunque, como hemos sugerido, el razonamiento que se lleva a cavo en el texto conduce hacia la acracia en donde ya no hay retorno para una simbólica del pater legibus, es decir un lugar en donde el canon y la convención que definen la simbólica de la justicia del padre legislador ya no opera, porque requiere de un nuevo procedimiento. 


\section{Bibliografía.}

AGUILAR J (2016a). "Sobre la crítica del proceso capitalista: su límite, su intervención y sus condiciones de posibilidad" en Oximora, Revista Internacional de ética y Política, número 9, pp. 166-186.

(2016b). "E1 Marx del proceso" en Theoría, Revista del colegio de Filosofía, número, 30-31, pp.171-190.

DRAPER H (1987). "The dictarship of the proletariat in Marx and Engels" en Monthy Rewiv Press, pp. 5-35.

KARATANI K (2003). Trnascritique, London: Massachusetts Instituto of technology.

WHITE H (1992). Metahistória, México: F.C.E. 